\title{
Detection of West Nile virus and tick-borne encephalitis virus in birds in Slovakia, using a universal primer set
}

\author{
Tomáš Csank $^{1}$ - Katarína Bhide ${ }^{1}$ Elena Bencúrová ${ }^{1} \cdot$ Saskia Dolinská $^{1}$. \\ Petra Drzewnioková $^{1} \cdot$ Peter Major $^{2} \cdot$ Luboš Korytár $^{3} \cdot$ Eva Bocková $^{4}$. \\ Mangesh Bhide $^{1} \cdot$ Juraj Pistl $^{1}$
}

Received: 8 September 2015/Accepted: 12 March 2016/Published online: 21 March 2016

(c) Springer-Verlag Wien 2016

\begin{abstract}
West Nile virus (WNV) is a mosquito-borne neurotropic pathogen that presents a major public health concern. Information on WNV prevalence and circulation in Slovakia is insufficient. Oral and cloacal swabs and bird brain samples were tested for flavivirus RNA by RT-PCR using newly designed generic primers. The species designation was confirmed by sequencing. WNV was detected in swab and brain samples, whereas one brain sample was positive for tick-borne encephalitis virus (TBEV). The WNV sequences clustered with lineages 1 and 2. These results confirm the circulation of WNV in birds in Slovakia and emphasize the risk of infection of humans and horses.
\end{abstract}

Keywords West Nile virus - Tick-borne encephalitis virus $\cdot$ Flavivirus $\cdot$ Birds $\cdot$ Raptors

T. Csank and K. Bhide contributed equally to this article.

Electronic supplementary material The online version of this article (doi:10.1007/s00705-016-2828-5) contains supplementary material, which is available to authorized users.

Juraj Pistl

pistl@uvlf.sk

1 Department of Microbiology and Immunology, University of Veterinary Medicine and Pharmacy in Košice, Komenského 73, 04181 Košice, Slovakia

2 Clinic for Birds and Exotic Animals, University of Veterinary Medicine and Pharmacy in Košice, Košice, Slovakia

3 Department of the Environment, Veterinary Legislation and Economy, University of Veterinary Medicine and Pharmacy in Košice, Košice, Slovakia

4 Department of Epizootology and Parasitology, University of Veterinary Medicine and Pharmacy in Košice, Košice, Slovakia
West Nile virus (WNV) is a neurotropic virus belonging to the genus Flavivirus (family Flaviviridae). WNV infects a wide spectrum of vertebrates; however, birds usually act as amplifying hosts and maintain the virus in a mosquitoavian-mosquito cycle. Humans and horses are considered dead-end hosts [1]. Migratory birds contribute to transmission and reintroduction of the virus from endemic areas into regions with sporadic outbreaks [2]. The first information on WNV in Slovakia dates back to the 1960s, when antibodies were found in human sera [3]. Between 1960 and 1978, WNV was isolated from Aedes cantans mosquitoes, and neutralizing antibodies were detected in $5.4 \%$ of birds, $5.3 \%$ of small mammals, $1 \%$ lagomorphs and $4.4 \%$ of free-living ungulates tested [4]. So far, no human cases of West Nile fever have been reported in Slovakia [5]. During 2008 and 2011 neutralizing antibodies were detected in $8.3 \%$ of unvaccinated horses [6]. A scientific report for the European Food Safety Authority and European Centre for Disease Prevention and Control reported $4.8 \% \mathrm{WNV}$ antibody prevalence in horses in Slovakia in 2012; however, no tested horses were seropositive in 2013. Up to now, there is no information about the situation in birds. Here, we focus on i) primer design for detection of several flaviviruses infecting animals and humans and ii) examination of bird swabs and brain samples for the presence of flaviviruses and their phylogenetic characterization.

The primers PanFlavi-F (nt 9135-9195; 5'WTRGCMATGACWGAYACHAC-3') and PanFlavi-R (nt 9470-9607; 5'-AACATGATGGGVAARMG-3') targeting a 365-bp region in the NS5 gene were designed based on flavivirus genome sequences (Online Resource File 1A) by Geneious Pro (Biomatters, New Zealand). cDNA from WNV strain goshawk-Hungary/04 (Accession no. DQ116961; a generous gift from Dr. Bakonyi Tamás; 
Szent István University, Department of Microbiology and Infectious Diseases, Hungary) was used for PCR with PanFlavi primers to assess its sensitivity. The specificity of PanFlavi primers was tested on 15 flaviviruses and other neurotropic RNA viruses (Online Resource File 1B). The PCR reaction was performed using $2 \mathrm{U}$ of DyNAzyme II DNA Polymerase (Thermo Scientific, Germany), containing each PanFlavi primer at a concentration of $2.5 \mu \mathrm{M}$ and $1 \mu \mathrm{l}$ of cDNA. The PCR product was separated in an agarose gel, and the DNA band of expected size was excised, purified using a QIAquick Gel Extraction Kit (QIAGEN, Germany) and quantified (NanoDrop 1000, Thermo Scientific, USA).

In order to investigate the circulation of WNV in birds, oral cavity and cloaca swabs and bird brain samples were tested by RT-PCR employing PanFlavi generic primers. Mist netting and bird ringing were carried out during April-November 2013 in three localities; Drienovec (Košice County; $48^{\circ} 36^{\prime} \mathrm{N} 20^{\circ} 54^{\prime} \mathrm{E}$ ), Zemplínska Teplica (Trebišov County; $48^{\circ} 38^{\prime} \mathrm{N} 21^{\circ} 35^{\prime} \mathrm{E}$ ) and Zajačia Valley (Levice County; $48^{\circ} 13^{\prime} \mathrm{N} 18^{\circ} 39^{\prime} \mathrm{E}$; Fig. 1). For detailed description of mist netting localities and bird species caught, see Online Resource File 2A. A total of 110 birds were caught and swabbed from the oral cavity and cloaca using two separate sterile cotton swabs (EUROTUBO ${ }^{\circledR}$ Collection swab, Deltalab, Spain), which were immersed in $1 \mathrm{ml}$ of AVL buffer (QIAGEN). Forty-five bird brain samples were obtained from the counties Nitra, Spišská Nová Ves, Košice-okolie, Košice and Trebišov (Fig. 1). Brain samples of two goshawks used for falconry in Nitra County were submitted for WNV detection. The owner reported apathy, anorexia, ataxia, balance disorders and sudden death. The bird species are listed in Online Resource File 2B. Twenty-five milligrams of brain tissue was immersed in $500 \mu \mathrm{l}$ of RNAlater (Ambion, United States). The tissue was homogenized in nuclease-free water and centrifuged at $10,000 \times \mathrm{g}$ for 30 minutes at $4{ }^{\circ} \mathrm{C}$, and the supernatant was stored at $-80{ }^{\circ} \mathrm{C}$. No virus isolation was carried out.

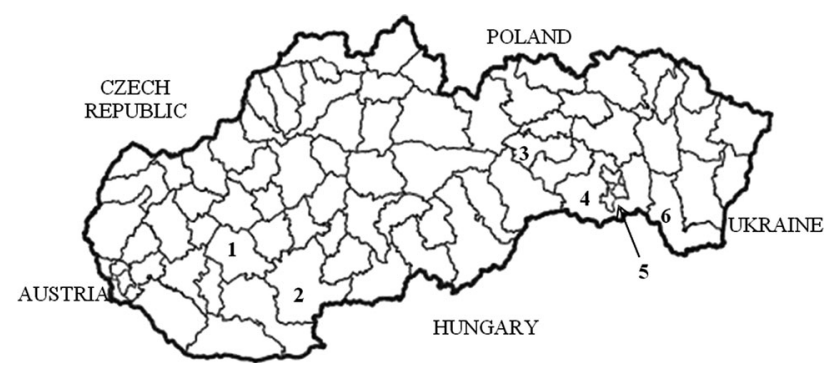

Fig. 1 Map of Slovakia showing the counties where swab and brain samples were obtained. The numbers correspond to counties: 1 , Nitra; 2, Levice; 3, Spišská Nová Ves; 4, Košice-okolie; 5, Košice; 6, Trebišov
Virus RNA from swabs and brain samples was isolated using a QIAamp Viral RNA Mini Kit (QIAGEN), and up to $5 \mu \mathrm{g}$ of extracted RNA was reverse transcribed using RevertAid H Minus Reverse Transcriptase (Thermo Scientific) employing a random hexamer (Thermo Scientific). The composition of the PCR mix, PCR thermal conditions and electrophoresis were the same as in the case of sensitivity and specificity standardization. Purified products were sequenced using a DNA analyzer (ABI PRISM 3700, Applied Biosystems). For sequence identification, BLAST search (http://blast.ncbi.nlm.nih.gov) was conducted, and partial flavivirus NS5 gene sequences were aligned by the CLUSTAL W method with reference strains of WNV lineages and TBEV subtypes (Online Resource 3A). Finally, a phylogenetic tree was generated using MEGA 6 software [7, 8]. All sequences detected in this study were submitted to the GenBank database.

Seventeen nanograms of extracted DNA was serially diluted tenfold. The last dilution yielding a visible DNA band of expected size was $1.7 \mathrm{fg} / \mu \mathrm{l}$ (Fig. 2). Amplification of the expected product was observed only for flaviviruses (Fig. 3) and not other viruses (Fig. 4).

A flavivirus NS5 gene fragment was detected in $21.8 \%$ of oral or cloacal swabs in birds of 10 species and in $26.7 \%$ of brain samples from five bird species (Table 1). Brain samples from two goshawks from Nitra County that died after showing neurological signs were both positive for flavivirus RNA. PCR products suitable for sequencing were obtained from all flavivirus RNA-positive swabs and from nine brain samples. BLAST analysis showed the presence of WNV in all swabs $(21.8 \%)$ and in $8(17.8 \%)$ brain samples, whereas one $(2.2 \%)$ brain sample was positive for TBEV. Phylogenetic analysis showed that WNV reference sequences were clearly clustered into five lineages and TBEV sequences were separated into three distinct subtypes (Online Resource 3B). WNV variants from Slovakia has been grouped into lineage $1(n=5)$ and lineage $2(\mathrm{n}=27)$, whereas TBEV clustered with the European Neudoerfl and Hypr subtypes.

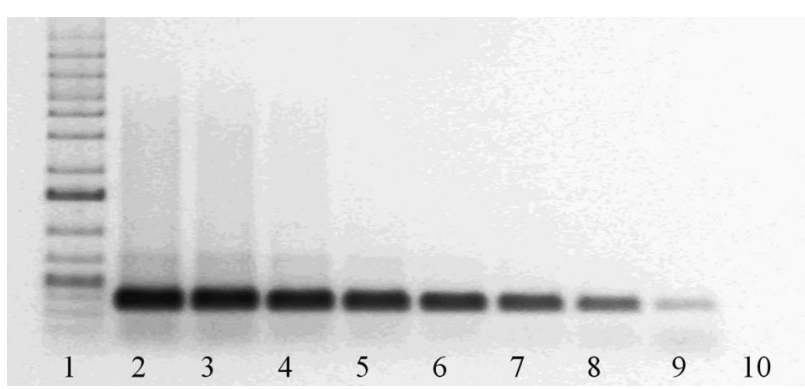

Fig. 2 Sensitivity testing of PanFlavi primers. 1, 1-kbp ladder; $2,17 \mathrm{ng} / \mu \mathrm{l} ; 3,1.7 \mathrm{ng} / \mu \mathrm{l} ; \quad 4,170 \mathrm{pg} / \mu \mathrm{l} ; \quad 5,17 \mathrm{pg} / \mu \mathrm{l} ; \quad 6,1.7 \mathrm{pg} / \mu \mathrm{l}$; 7, $170 \mathrm{fg} / \mu \mathrm{l} ; 8,17 \mathrm{fg} / \mu \mathrm{l} ; 9,1.7 \mathrm{fg} / \mu \mathrm{l} ; 10,0.7 \mathrm{fg} / \mu \mathrm{l}$ 


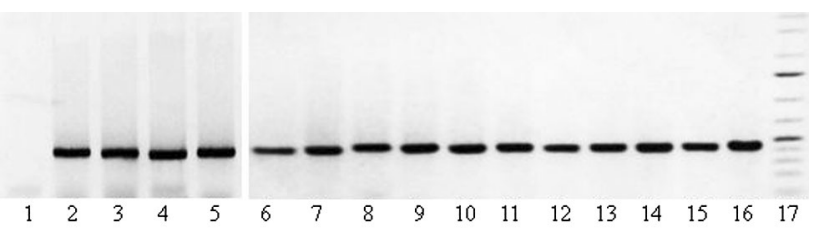

Fig. 3 Specificity of PanFlavi primers from different flaviviruses. 1, negative control (water); 2, dengue virus (DENV)-1; 3, DENV-2; 4, DENV-3; 5, DENV-4; 6, Usutu virus; 7, Zika virus; 8, WNV lineage 1; 9, WNV lineage 2; 10, yellow fever virus; 11, TBEV strain Hypr; 12, TBEV strain Kumlinge; 13, TBEV strain Kokkola; 14, TBEV strain Buryatia; 15, TBEV unsigned strain; 16, Japanese encephalitis virus; 17, 1-kbp ladder

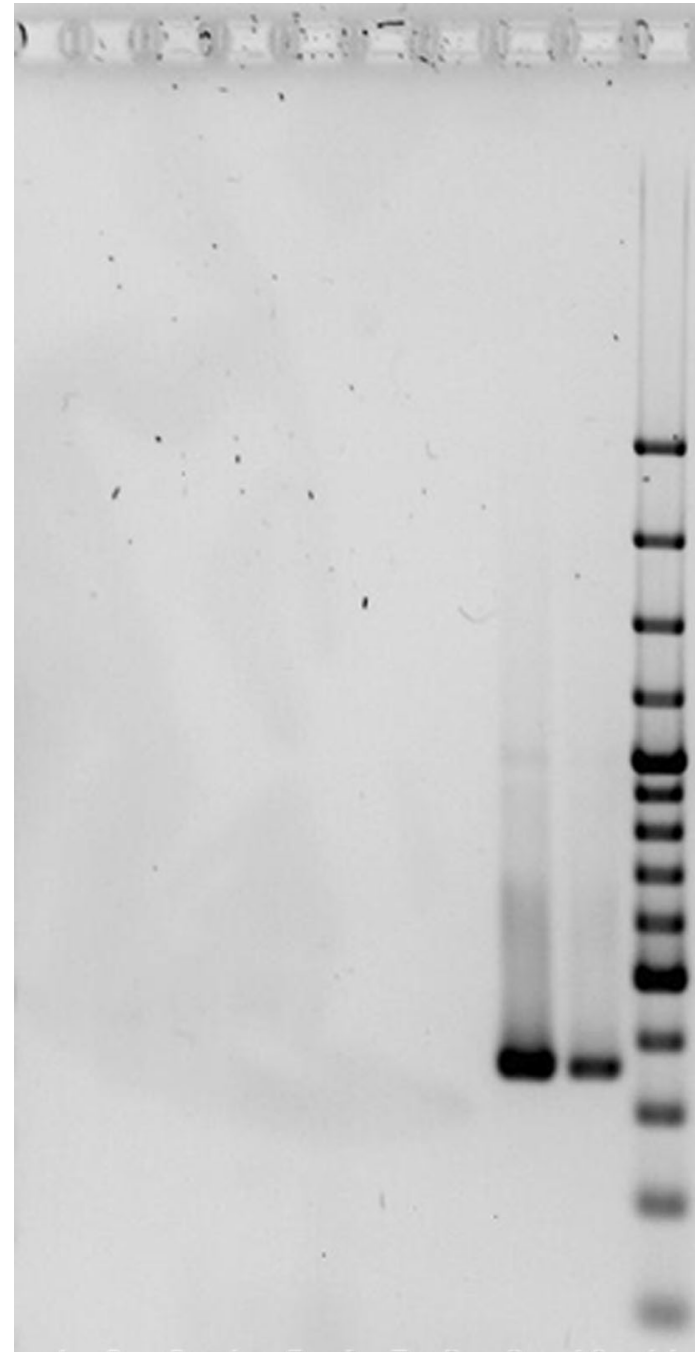

$\begin{array}{lllllllllll}1 & 2 & 3 & 4 & 5 & 6 & 7 & 8 & 9 & 10 & 11\end{array}$

Fig. 4 Specificity of PanFlavi primers with non-flaviviruses. 1, influenza virus A (IVA) H5N2; 2, IVA H5N1; 3, Newcastle disease virus strain La Sota; 4, pigeon paramyxovirus 1 strain Vh273/06; 5, Tribeč virus; 6 , Kemerovo virus; 8 , rabies virus; 9, WNV strain goshawk-Hungary/04; 10, TBEV strain Hypr; 11, 100-bp ladder
The nucleotide sequence variations among WNV sequences from Slovakia within lineage 1 ranged between 0.014 and 0.145 . As expected, the largest nucleotide sequence difference was observed with the Australian Kunjin virus; however, the closest reference strain was Egypt 101, with 0.091 and 0.144 , respectively (Online Resource 3C). Despite the higher number, lower nucleotide sequence divergence 0.000-0.098 was observed between variants grouped into lineage 2 (Online Resource 3D). This node is divided in two groups with a bootstrap value of $99 \%$. A single sequence from Eurasian Tree Sparrow (KJ725276) forms a single branch. The closest reference strains were ArD76104 and LEIV-3266Ukr, with 0.050 and 0.053 sequence divergence, respectively. Brain samples KJ725292 and KJ725293 from Nitra County collected from goshawks that died after showing neurological clinical signs were also positive for WNV RNA. The closest reference sequences were from Hungary, Austria, Serbia and Greece, with nucleotide sequence differences ranging between 0.023 and 0.029 for KJ725292 and between 0.044 and 0.050 for KJ725293. Three sequences from a hawfinch (KJ725270), a European greenfinch (KJ725261) and a common nightingale (KJ725259) had identical nucleotide sequences (Online Resource 3D). These birds were caught in the Drienovec area at two distinct sampling times (April and October), and the viral sequences were similar to European reference strains. Tick-borne encephalitis virus sequence KJ725258, obtained from the brain of a common buzzard that was found dead was clustered with European subtypes Hypr and Neudoerfl (Online Resource 3B) with $0.041 \pm 0.011$ and $0.069 \pm 0.014$ nucleotide sequence divergence, respectively.

Standardization of a molecular assay for simultaneous detection of several flaviviruses is challenging, considering the genetic diversity of these viruses. We designed primers for PCR in combination with agarose gel electrophoresis for detection of 15 flaviviruses. The species was identified by sequencing. The sensitivity of the PCR reaction employing PanFlavi primers was evaluated using serial dilutions of an amplified NS5 fragment and was found to be $1.7 \mathrm{fg} / \mu \mathrm{l}$. We chose this approach because WNV is a containment level 3 pathogen. Based on the molecular weight and the concentration of the PCR product one can calculate the number of copies, which in our case was $4.75 \times 10^{3}$ copies per reaction. In comparison, Kuno and colleagues achieved a sensitivity limits of greater than 3 $\log _{10}$ PFU/ml by single-round PCR, but the limits by several semi-nested PCR procedures were lower than $1 \mathrm{PFU} / \mathrm{ml}$. Using MA and cFD2 primers, they were able to detect members of 66 flavivirus species [9]. In a different study by Scaramozzino et al., a previously described primer pair (MA, cFD2) was modified and used in a 
Table 1 Detection of flavivirus RNA in birds

\begin{tabular}{lll}
\hline Bird species & $\begin{array}{l}\text { No. of caught birds of a species/no. } \\
\text { flavivirus RNA positive }\end{array}$ & $\begin{array}{l}\text { No. of brain samples of species/no. } \\
\text { flavivirus RNA positive }\end{array}$ \\
\hline Long-eared Owl & $1 / 1$ & \\
Hawfinch & $2 / 1$ & \\
European Robin & $3 / 1$ & \\
European Greenfinch & $10 / 2$ & \\
Common Nightingale & $1 / 1$ & \\
Eurasian Great Tit & $7 / 3$ & \\
House Sparrow & $16 / 6$ & \\
Eurasian Tree Sparrow & $29 / 4$ & \\
Wood Warbler & $1 / 1$ & $2 / 2$ \\
Blackcap & $17 / 4$ & $4 / 3$ \\
Northern Goshawk & & $2 / 1$ \\
Common Buzzard & & $11 / 5$ \\
Eurasian Sparrow hawk & & $2 / 1$ \\
Common Kestrel & & $45^{\mathrm{a}} / 12$ \\
Eurasian Blackbird & & \\
Total swab samples & $110^{\mathrm{a}} / 24$ & \\
\hline
\end{tabular}

a Total number of swab samples analyzed for the presence of flavivirus RNA. For detailed species distribution and the number of birds caught, see Online Resource Files 2A and 2B heminested and real-time PCR. However, the reactions were tested only on eight flaviviruses, and the sensitivity increased [10]. Attempts will be made to test PanFlavi PCR at serial dilutions with known virus titers and increase the sensitivity either by primer or PCR modifications. Although the fragment of NS5 gene sequenced and used for phylogeny in our study is too short for comprehensive phylogenetic analysis, the accurate clustering of reference strains shows that it is useful as a first-line method for screening of flaviviruses [11].

Our results support suggestions of northward spreading of WNV lineage 2 [12]. Lineage 2 sequences from Slovakia were grouped into several clusters. One of them is a group of sequences, KJ725259, KJ725261 and KJ725270, that showed no nucleotide sequence divergence. These viruses were from swabs taken from three different bird species (Hawfinch, European Greenfinch and Common Nightingale) during two different sampling times (April and October) in the Drienovec area. Circulation of WNV strains for longer period has been described [13]; however, samples from a longer period need to be analyzed, and the whole genome or multiple genes should be sequenced to prove the circulation of a certain WNV strain in this area.

Brain samples of two northern goshawks that died after onset of neurological signs were submitted for WNV detection. The KJ725292 and KJ725293 sequences were $97.3 \%$ and $95.6 \%$ identical to lineage 2 reference strains detected during human or bird outbreaks in Greece, Serbia, Italy, Austria and Hungary. Taking into account the high WNV prevalence in the analyzed bird samples, the recent
WNV epidemics in the neighboring countries, and the nonspecific clinical signs preceding death [14], it is likely that the disease has been misdiagnosed or overlooked until now in birds in Slovakia.

Detection of TBEV in the brain of a common buzzard proves the usefulness of PanFlavi primers in combination with sequencing for monitoring of flaviviruses. TBEV is endemic in Slovakia, and the virus has been detected in birds [15]. Recently, Mikryukova et al. confirmed the involvement of wild birds in the formation of natural foci of TBEV in the Tomsk region in Russia. They found antigen or viral RNA in almost $70 \%$ of bird species tested. However, the highest prevalence was found in fieldfares, common redstarts, and brambling birds. This might be explained by frequent contact with infected ticks rather than susceptibility to infection [16]. Rodents are major maintenance and reservoir hosts of TBEV. They are abundant in the infection foci and are readily infested with large numbers of Ixodes ricinus ticks [17]. We found TBEV RNA in the brain of a raptor, suggesting a possible spillover of the virus to predators.

The following conclusions can be drawn from this study: i) The simultaneous detection of WNV and TBEV by RT-PCR employing generic PanFlavi primers targeting the NS5 gene followed by sequencing is useful in the monitoring of flaviviruses in birds; however, attempts should be made to increase the sensitivity of the assay and to compare its specificity with other PCR methods. ii) The high proportion of lineage 2 variants in wild birds indicates northward spread and gives a more accurate view of the 
epidemiology of WNV. iii) The presence of WNV RNA in the brain of two goshawks that died after showing neurological signs is the first evidence of West Nile fever in raptors in Slovakia.

Acknowledgments This study was supported by grants APVV0036-10 and VEGA-1/0054/12. The infrastructure was supported by ITMS - 26220120002 (Infektzoon - Centrum of excellence for infections of animals and zoonoses) and ITMS 26220220185 (MediPark. Košice). The tick-borne encephalitis virus strain Hypr cDNA was kindly provided by Dr. Boris Klempa (lnstitute of Virology, Slovak Academy of Science) under the framework of FP7 as CAPACITIES project EVA.

\section{References}

1. Bowen RA, Nemeth NM (2007) Experimental infections with West Nile virus. Curr Opin Infect Dis 20(3):293-297. doi:10. 1097/QCO.0b013e32816b5cad

2. Burke DS, Monath TP (2001) Flaviviruses. In: Knipe DM, Howley PM (eds) Fields virology, 4th edn. Lippincott Wiliams \& Wilkins, Philadelphia, pp 1043-1125

3. Grešíková M, Sekeyova M (1967) Haemagglutination-inhibiting antibodies against arboviruses in the population of Slovakia. J Hyg Epidemiol 11:417-421

4. Kožuch O, Nosek J, Labuda M (1980) Arboviruses occuring in western Slovakia and their hosts. In: Labuda M, Calisher $\mathrm{CH}$ (eds) Proceedings of the international symposium on new aspects in ecology of arboviruses, June, 1979, Smolenice near Bratislava. Institute of Virology, Slovak Academy of Sciences, pp 323-333

5. EFSA, ECDPC (2015) The European Union summary report on trends and sources of zoonoses, zoonotic agents and food-borne outbreaks in 2013. EFSA J 13(3994):126. doi:10.2903/j.efsa. 2015.3991

6. Hubalek Z, Ludvikova E, Jahn P, Treml F, Rudolf I, Svobodova P, Sikutova S, Betasova L, Bires J, Mojzis M, Tinak M, Boldizar M, Citsonova G, Stassikova Z (2013) West Nile Virus equine serosurvey in the Czech and Slovak republics. Vector Borne Zoonotic Dis 13:733-738. doi:10.1089/vbz.2012.1159

7. Tamura K, Stecher G, Peterson D, Filipski A, Kumar S (2013) MEGA6: molecular evolutionary genetics analysis version 6.0. Mol Biol Evol 30(12):2725-2729. doi:10.1093/molbev/mst197
8. Kimura M (1980) A simple method for estimating evolutionary rates of base substitutions through comparative studies of nucleotide sequences. J Mol Evol 16(2):111-120

9. Kuno G (1998) Universal diagnostic RT-PCR protocol for arboviruses. J Virol Methods 72(1):27-41. doi:10.1016/S01660934(98)00003-2

10. Scaramozzino N, Crance J-M, Jouan A, DeBriel DA, Fo Stoll, Garin D (2001) Comparison of flavivirus universal primer pairs and development of a rapid, highly sensitive heminested reverse transcription-PCR assay for detection of flaviviruses targeted to a conserved region of the NS5 gene sequences. J Clin Microbiol 39(5):1922-1927. doi:10.1128/jcm.39.5.1922-1927.2001

11. Moureau G, Temmam S, Gonzalez JP, Charrel RN, Grard G, De Lamballerie X (2007) A real-time RT-PCR method for the universal detection and identification of flaviviruses. Vector Borne Zoonotic Dis 7(4):467-477. doi:10.1089/vbz.2007.0206

12. Rudolf I, Bakonyi T, Sebesta O, Mendel J, Pesko J, Betasova L, Blazejova H, Venclikova K, Strakova P, Nowotny N, Hubalek Z (2014) West Nile virus lineage 2 isolated from Culex modestus mosquitoes in the Czech Republic, 2013: expansion of the European WNV endemic area to the North? Eurosurveillance 19(31):2-5

13. Barzon L, Pacenti M, Franchin E, Lavezzo E, Masi G, Squarzon L, Pagni S, Toppo S, Russo F, Cattai M, Cusinato R, Palu G (2013) Whole genome sequencing and phylogenetic analysis of West Nile virus lineage 1 and lineage 2 from human cases of infection, Italy, August 2013. Euro Surveill 18(38)

14. Gamino V, Hofle U (2013) Pathology and tissue tropism of natural West Nile virus infection in birds: a review. Vet Res 44:39. doi:10.1186/1297-9716-44-39

15. Ernek E, Kozuch O, Nosek J (1977) Virus neutralizing antibodies to arboviruses in birds of the order Anseriformes in Czechoslovakia. Acta Virologica 19:349-353

16. Mikryukova TP, Moskvitina NS, Kononova YV, Korobitsyn IG, Kartashov MY, Tyuten Kov OY, Protopopova EV, Romanenko VN, Chausov EV, Gashkov SI, Konovalova SN, Moskvitin SS, Tupota NL, Sementsova AO, Ternovoi VA, Loktev VB (2014) Surveillance of tick-borne encephalitis virus in wild birds and ticks in Tomsk city and its suburbs (Western Siberia). Ticks Tick Borne Dis 5(2):145-151. doi:10.1016/j.ttbdis.2013.10.004

17. Nuttall PA, Labuda M (1994) Tick-borne encepahalitis subgroup. In: Sonenshine DE, Mather TN (eds) Ecological dynamics of tick-borne zoonoses. Oxford University Press, New York, pp 351-391 